\title{
Family caregiver perspectives on caring for ventilator-assisted individuals at home
}

\author{
Rachael Evans MBChB PhD ${ }^{1,2}$, Michael Catapano ${ }^{1}$, Dina Brooks $\mathrm{PhD}^{1,3}$, \\ Roger Goldstein $\mathrm{MD}^{1,2,3}$, Monica Avendano $\mathrm{MD}^{1,2}$
}

\begin{abstract}
R Evans, M Catapano, D Brooks, R Goldstein, M Avendano. Family caregiver perspectives on caring for ventilator-assisted individuals at home. Can Respir J 2012;19(6):373-379.
\end{abstract}

BACKGROUND: The trend of patients who are invasively ventilated to prefer home care is one that benefits both the patient and the health care system. However, this assumes a role for patients' family members to become informal caregivers.

OBJECTIVE: To explore the impact of caring for a ventilator-assisted individual on informal caregivers.

METHODS: A descriptive design with semistructured caregiver interviews and the Caregiver Burden Inventory were used. Participants were informal caregivers of a family member with a progressive neuromuscular disease on invasive ventilation for at least six months. Transcript coding was performed and regularly reviewed, and recruitment continued until data saturation. Qualitative analysis was based on 'thematic analysis'.

RESULTS: A total of 21 caregivers were interviewed. Five themes developed: a sense of duty; restriction of day-to-day life; physical and emotional burden; training and education; and the need for more paid support. Caregivers described a sense of duty to take care of loved ones, but suffered a significant restriction of their own time with a negative impact on their physical and mental health. The initial transfer home was highlighted as the most stressful part of the process. The Caregiver Burden Inventory scores supported a high level of burden: median 49 (interquartile range 39.5 to 53.0) of a maximum 96.

CONCLUSION: Homecare for ventilator-assisted individuals with progressive neuromuscular disease causes significant burden to informal caregivers. Approaches to lessen this burden, such as increased paid care, improved professional support and respite care, may enable home ventilation to be a more sustainable modality of care.

Key Words: Burden of care; Family caregivers; Home ventilation; Mechanical ventilation; Neuromuscular disease

Several intersecting developments have resulted in increased interest $\checkmark$ to help ventilator-assisted individuals (VAIs) return home (1-3). These include more portable and easier to use ventilators $(4,5)$, the trend toward community - rather than institutional - living, increased availability of home support services (6), the pressure to open intensive care unit (ICU) beds to serve complex unstable patients and improved access to information regarding long-term ventilation $(2,7)$. Patients receiving invasive ventilation often remain in an ICU until they can be transferred to a specially designed, long-term ventilation unit or to the community. Those going home are often admitted to an intermediate location for multidisciplinary optimization of function and home training for themselves and their caregivers.

Family members are essential to establishing a sustainable, stable and rewarding environment that enables a VAI to live at home while receiving adequate care. Although limited paid care might be provided through community services or private funding, family members often assume substantial responsibilities. Caregivers may include individuals 'who provide personal care or other supportive services for an elderly parent, other than a relative or friend'. Caregiver services range from

\section{Les perspectives des aidants familiaux à l'égard des soins aux personnes sous assistance respiratoire à domicile}

HISTORIQUE : La tendance des patients sous assistance respiratoire invasive à préférer les soins à domicile profite à la fois aux patients et au système de santé. Cependant, les membres de la famille doivent alors devenir des aidants.

OBJECTIF : Explorer les conséquences des soins aux personnes sous assistance respiratoire sur les aidants.

MÉTHODOLOGIE : Les chercheurs ont utilisé une méthodologie descriptive composée d'entrevues semi-structurées avec les aidants et de l'inventaire du fardeau des soignants. Les participants étaient les aidants d'un membre de la famille atteint d'une maladie neuromusculaire évolutive sous assistance respiratoire invasive depuis au moins six mois. Les chercheurs ont procédé au codage des relevés, qu'ils ont révisé régulièrement, et le recrutement s'est poursuivi jusqu'à la saturation des données. Ils ont fondé l'analyse qualitative sur une "analyse thématique ».

RÉSULTATS : Les chercheurs ont interviewé un total de 21 aidants. Ils ont dégagé cinq thèmes : le sentiment de responsabilité, les entraves à la vie quotidienne, le fardeau physique et affectif, la formation et l'éducation et le besoin d'un plus grand soutien rémunéré. Les aidants décrivaient se sentir responsables de s'occuper de leur proche, mais subissaient des entraves considérables à leur propre temps, ce qui nuisait à leur santé physique et mentale. Le transfert initial à domicile ressortait comme la partie la plus stressante du processus. Les indices de l'inventaire du fardeau des soignants faisaient état d'un fardeau élevé : médiane de 49 (plage interquartile de 39,5 à 53,0), pour un maximum de 96 .

CONCLUSION : Les soins à domicile des personnes atteintes d'une maladie neuromusculaire évolutive qui sont sous assistance respiratoire constituent un fardeau important pour les aidants. Les démarches pour atténuer ce fardeau, telles que l'augmentation des soins rémunérés, l'amélioration du soutien professionnel et les soins de répit, peuvent contribuer à faire de l'assistance respiratoire à domicile une modalité de soins plus viable.

intimate care such as dressing, bathing and feeding, to more impersonal services such as housecleaning, meal preparation, financial management and transportation (8). Another interpretation is that the term 'caregiver' applies to 'the person most closely involved in maintaining a person's ability to live independently at home' (9). The burden of a caregiver has been described as 'the oppressive or worrisome load borne by people providing direct care for the chronically ill' (10).

When accepting their family member at home, informal caregivers may have a very limited understanding of their underlying diagnosis and rate of disease progression $(11,12)$, thereby underestimating the potential caregiver burden $(13,14)$.

A few reports have described the quality of life $(15,16)$ and attitudes (17) toward treatment of VAIs and neuromuscular disease (NMD). Kaub et al (18) noted that family caregivers rated their quality of life lower than that of the VAI with amyotrophic lateral sclerosis (ALS). However, most reports have not included the impact of providing care on family members. Existing studies on caregivers have focused either on ALS before invasive mechanical support (19) or included patients on both noninvasive and invasive mechanical

${ }^{1}$ Department of Respiratory Medicine, West Park Healthcare Centre; ${ }^{2}$ Department of Medicine; ${ }^{3}$ Department of Physical Therapy, University of

Toronto, Toronto, Ontario

Correspondence: Dr Roger Goldstein, West Park Healthcare Centre, 82 Buttonwood Avenue, Toronto, Ontario M5P 2 P3.

Telephone 416-243-3631, fax 416-243-3696, e-mail rgoldstein@westpark.org 
ventilation (20). Chio et al (13) quantitatively described caregiver burden in patients with ALS, but only two of 60 required invasive mechanical ventilation. Using semistructured interviews, Van Kesteren et al (20) reported a higher level of stress on family caregivers for patients requiring invasive versus noninvasive ventilation, with 33 of 38 having an NMD. The high burden of care associated with NMDs, even before ventilation is required, is increasingly recognized because caregivers report personal and social restrictions, as well as physical and emotional problems, which increase with disease progression $(19,21,22)$. The burden of caring for an individual with the combination of NMD and requiring invasive mechanical ventilation is likely to be even greater and unlikely to be reflected by the literature focusing on caregivers of patients with each condition in isolation.

Although there is some universality in the challenges for all family caregivers of patients with chronic conditions, it is likely to be particularly challenging for those caring for patients with NMDs who require invasive ventilation with all of the associated technical demands and, at this stage in their condition, there is often profound physical impairment often including quadriplegia with dysfunctional communication and feeding. Data from caregivers (spouses) of other chronic diseases may also not be comparable; studies involving patients with dementia, Parkinson's disease or strokes showed that it was the cognitive impairment of the patients that most affected the caregiver burden (23) whereas in ALS, cognition is often preserved.

A clearer understanding of the burden on family caregivers will assist health care and social services to support home-based care of the VAI. In the present study, we report on the perspectives of family informal caregivers on the burden associated with caring for invasively ventilated patients with NMD at home.

\section{METHODS}

Study design

The present study was of a 'mixed-method' design that used both qualitative semistructured interviews and a questionnaire. The qualitative analysis was based on 'thematic analysis' (24).

\section{Participant recruitment}

Ethics approval was obtained from the local hospital research ethics board. Caregivers recruited were $>18$ years of age and had provided informal (ie, unpaid) care at home for an invasively ventilated family member with progressive NMD for at least six months. All of the VAIs had been transferred from the ICU to a transitional unit for home ventilation and all had received training before being transitioned home. Caregivers whose family member was receiving full-time paid attendant care were excluded from the study.

Informal caregivers were sequentially recruited from the local clinical database of patients receiving long-term invasive ventilation based on the study inclusion criteria. Primary informal caregivers (defined as the caregiver providing the majority of care) were initially identified and contacted by a clinical team member requesting permission for the research team to contact them. If they agreed, a member of the research team contacted them (typically by telephone) and briefly discussed the study. An information leaflet was then sent by mail and the caregivers were given several days to consider participating in the study. A follow-up telephone call was made by the research team to discuss any questions and to organize a convenient time to obtain written consent and proceed to the interviews if willing. The primary caregiver also identified a secondary caregiver and consent was then sought from the secondary caregiver using the same process.

If the informal caregiver completed the study, consent was also sought from the patient to allow their clinical information to be retrieved by the research team and used for publication. The motor and cognitive part of the Functional Independence Measure (25) was used to describe the level of the patients' disability (26). It has 18 questions with the responses chosen from a 7-point Likert rating system, designed for health care personnel to evaluate both motor and cognitive skills. Higher scores represent higher function.

\section{Data collection}

Semistructured interview: Caregiver demographics were retrieved from the medical record and the VAIs' level of dependency was assessed by a clinician (MA or RG). Face-to-face individual interviews were then conducted using a semistructured questionnaire (designed by the clinical research team using the theoretical understanding of caregiver burden) with open-ended questions plus prompts. The questions were designed to explore a range of issues pertaining to caregiving (Figure 1) and to encourage caregivers to reflect and describe the impact of the changes that had occurred as a result of providing care for the VAI (27). Caregivers were encouraged to deviate from the interview questions and new themes were noted. Interviews (approximately $40 \mathrm{~min}$ in duration) were audio recorded and transcribed verbatim by personnel outside of the research team.

Caregiver Burden Inventory: After the completion of the semistructured interview, caregivers were requested to complete the Caregiver Burden Inventory (CBI). This is a 24 -item, validated, reproducible, multidimensional self-report instrument that quantitatively assesses caregiver burden $(28,29)$, and has been previously used to assess caregivers of patients with neurological and psychiatric disorders $(13,30,31)$. It addresses five common areas of burden: time-dependent burden (due to the restriction of time); physical burden (feelings of fatigue and chronic health problems); social burden (relationships with family members and coworkers); emotional burden (negative or positive feelings toward the patient); and developmental burden (the perception of being excluded from the expectations and opportunities enjoyed by one's peers).

\section{Data analysis}

Semistructured interview: Data analysis began after the first four interviews and continued throughout the data collection period. Data analysis was based on 'thematic analysis' (32). There are six recognized phases to this approach: familiarization with data; generating initial codes; searching for themes; reviewing themes; defining and naming themes; and producing the report.

All transcripts were analyzed and coded by one member of the research team $(\mathrm{MC})$, which were then recoded independently by at least one other member (RE and DB) to ensure validity of the themes. An interdisciplinary research team of health care professionals (RE, $\mathrm{MC}, \mathrm{DB}, \mathrm{RG}, \mathrm{MA}$ ) met regularly, to validate emerging themes and impressions of the cases. Discussions were focused on explanations, speculations or hypotheses about the cases, and alternative explanations and interpretations to guide further analysis. Following these meetings, the semistructured interview questions were adapted and revised. Recruitment was considered to be complete when conclusions were logically consistent, incongruencies were accounted for, and alternative interpretations were explored and accommodated or rejected based on sound, explicit reasoning (ie, data saturation). The transcripts were then recoded once themes were agreed on by the team.

\section{CBI}

CBI scores were calculated for the total level of burden (higher scores reflecting a higher burden) and also for each of the five domains. The scores were expressed as median and interquartile range.

\section{RESULTS}

\section{Participants}

The participant flow diagram is presented in Figure 2 and the characteristics of the 21 caregivers who participated are described in Table 1. More than two-thirds of the family caregivers had college or university education. Of the 12 VAIs, (mean [ \pm SD] age $45 \pm 13$ years), seven had ALS, four had Duchenne muscular dystrophy and one had myotonic dystrophy. All were invasively ventilated for a mean of $8 \pm 5$ years and required $24 \mathrm{~h}$ ventilation. The majority of patients (all except two) were initially ventilated under emergency circumstances. The median VAI motor and cognitive functional independence measure scores were 14.5 of 


\section{INTERVIEW GUIDE (SEMI-STRUCTURED QUESTIONS)}

-Did you receive any kind of formal or informal training in care giving? Probes: What kind? How long?

- Can you talk about how this training prepared you for your role as a care giver? Probes: what was helpful? Anything unhelpful? Anything you can suggest to include that you would have found helpful?

-Talk me through a typical day? Is this different on a weekend?

- What aspects of care giving do you enjoy? Are there some things that are less enjoyable or difficult?

-What are the tasks you are expected to do as part of your care giving? Are there any barriers (things that make it harder? Are there any enablers (things that make it easier)? How do you work out how a task will be done? Are there ever any problems with this approach?

-Can you talk to me about the personal relationship you have with ventilator-user? What makes the relationship work well? What gets in the way?

-There have obviously been some changes in your life as a result of being a caregiver. I would really like to understand those if you wouldn't mind talking to me about them.

1.Can you describe for me if or how your health has change due to care giving?

2.Are there any changes in your financial situation? What are they?

3.How has your leisure time been affected, whether that is your social life or your hobbies?

4. How do you feel prompt; how is your mood?

-How have things changed since ventilation was initiated? Probes: Family dynamic? Work situation?

-What was the situation like initially coming home from the hospital? How does it compare to now? How long did it take to adjust?

-What is it like to have your family member at home compared to when he/she was being taken care of in the hospital?

-Doyou see any changes in the future of your caring for the ventilator user? If so, what changes?

-How did your relative start on invasive ventilation? Was it planned or as an emergency? Were you aware that at some point your relative may need ventilation? (If $\mathrm{Y}$ ) who talked to you about it? Is there anything that could have been done differently beforehand that would have helped you now? Would you choose LTMV or advise a family member to go on LTMV after what you know now?

-We hope this study will help to support positive changes for caregivers of ventilator assisted family members. To that end is there anything you think we should know that we haven't asked about? Anything you'd like to see changed? Anything that you feel is critical to keep the same?

- We are hoping to get a very realistic view of what it takes to care for someone on Long-Term Mechanical Ventilation, so if you remember anything that you feel is important for us to know that we have not touched on please feel free to call me.

Figure 1) The semistructured interview questions. LTMV Long-term mechanical ventilation; Y Yes

77 (IQR 14.0 to 16.5 ) and 27.0 of 35 (IQR 24.6 to 29.4), respectively. Formal caregivers were provided through the provincial (Ontario) government-funded home care program, with VAIs receiving $47.8 \pm 5.5 \mathrm{~h}$ per week of home care. Those able to supplement this with private funding (four of 12 ) received a total of $161.3 \pm 11.5 \mathrm{~h}$ per week of predominantly nursing assistance.

The individual total CBI scores are shown in Table 1 and the five domains for both primary and secondary caregivers are shown in Table 2.

The interview results were grouped into five categories, each representing the main themes that developed through interview responses and CBI scores. These categories were as follows: a sense of duty; restriction of day-to-day life; physical and emotional burden; training and education; the need for more paid support. The following section describes the categories of caregiver burden, using direct quotes from the caregivers.

\section{Sense of duty}

In most interviews (15 of 21), a sense of obligation to be an informal caregiver emerged. This was attributable to their relationship to the VAI family member.

Primary caregiver (PC)3: Suck it up, march forward, no whining, do your job, do your duty, maintain your honor, fulfill your obligation.

Obligation was expressed together with the perception that their loved one would not live as long or as happy a life if institutionally based, rather than home based.

PC8: I think that if he wasn't at home he wouldn't be here today.

PC1: If I were to leave him in a different place, not everyone is going to be like his mom and dad.

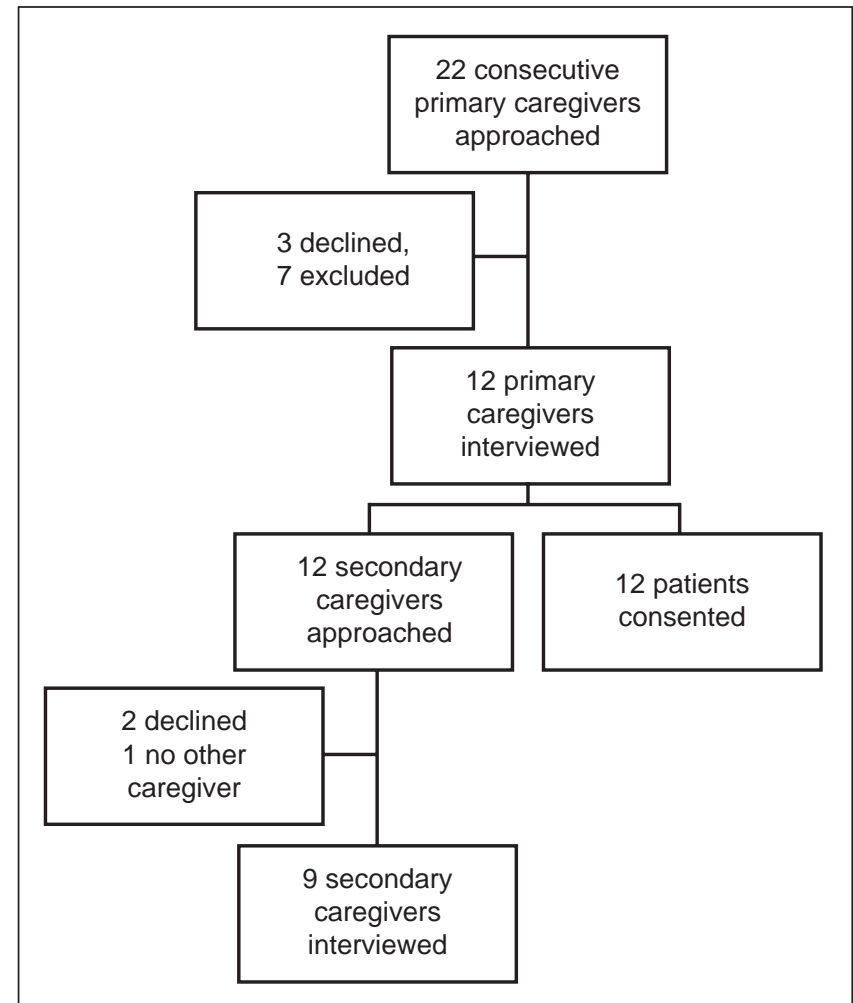

Figure 2) Participant flow diagram 
TABLE 1

Description of family caregivers

\begin{tabular}{|c|c|c|c|c|c|c|c|c|c|c|}
\hline $\begin{array}{l}\text { Primary } \\
\text { caregiver (PC) }\end{array}$ & $\begin{array}{l}\text { Age, } \\
\text { years }\end{array}$ & Sex & $\begin{array}{l}\text { Relationship } \\
\text { to patient }\end{array}$ & $\begin{array}{l}\text { CBI total } \\
\text { score }\end{array}$ & $\begin{array}{l}\text { Secondary } \\
\text { caregiver (SC) }\end{array}$ & $\begin{array}{l}\text { Age, } \\
\text { years }\end{array}$ & Sex & $\begin{array}{c}\text { Relationship to } \\
\text { patient }\end{array}$ & $\begin{array}{l}\text { CBI total } \\
\text { score }\end{array}$ & $\begin{array}{c}\text { Weekly paid } \\
\text { care, } \mathrm{h}\end{array}$ \\
\hline$\overline{P C 1}$ & 64 & Female & Mother & 48 & $\mathrm{SC1}$ & 66 & Male & Father & 53 & 10 \\
\hline PC2 & 30 & Male & Son & 60 & $\mathrm{SC} 2$ & 31 & Female & Daughter & 55 & 44 \\
\hline PC3 & 63 & Male & Husband & 53 & SC3 & 76 & Male & Father & 36 & 42 \\
\hline PC4 & 58 & Female & Mother & 54 & $\mathrm{SC} 4$ & $N / A$ & N/A & $\mathrm{N} / \mathrm{A}$ & N/A & 10 \\
\hline PC5* & 49 & Female & Wife & 53 & SC5 & 26 & Male & Son & 16 & 98 \\
\hline PC6 & 44 & Female & Wife & 35 & SC6 & 66 & Male & Father & 15 & 52.5 \\
\hline$P C 7 *$ & 65 & Male & Father & 34 & $\mathrm{SC} 7$ & 62 & Female & Mother & 53 & 140 \\
\hline PC8 & 47 & Female & Wife & 49 & SC8 & 46 & Female & Sister & 48 & 59 \\
\hline PC9 & 64 & Female & Mother & 50 & SC9 & 66 & Male & Father & 43 & 38 \\
\hline PC10 & 65 & Female & Mother & 44 & SC10 & $\mathrm{N} / \mathrm{A}$ & N/A & N/A & $\mathrm{N} / \mathrm{A}$ & 14 \\
\hline PC11* & 51 & Female & Wife & 42 & SC11 & $\mathrm{N} / \mathrm{A}$ & N/A & $\mathrm{N} / \mathrm{A}$ & N/A & 148 \\
\hline PC12* & 62 & Female & Wife & 23 & SC12 & 30 & Female & Daughter & 11 & 140 \\
\hline
\end{tabular}

${ }^{*}$ Patient received direct funding. CBI Caregiver Burden Inventory; N/A Not available

TABLE 2

Results of the Caregiver Burden Inventory

\begin{tabular}{|c|c|c|}
\hline \multirow{2}{*}{$\begin{array}{l}\text { Caregiver Burden Inventory } \\
\text { domain scores }\end{array}$} & \multicolumn{2}{|c|}{ Caregiver } \\
\hline & Primary $(n=12)$ & Secondary $(n=9)$ \\
\hline $\begin{array}{l}\text { Total score } \\
\qquad(\text { maximum }=96)\end{array}$ & $49.0(39.5-53.0)$ & $42.5(21.0-51.7)$ \\
\hline $\begin{array}{l}\text { Time-dependent burden } \\
\quad(\text { maximum }=20)\end{array}$ & $18.0(16.5-19.5)$ & $17.0(13.8-18.5)$ \\
\hline $\begin{array}{l}\text { Developmental burden } \\
\quad(\text { maximum }=20)\end{array}$ & $13.0(10.0-13.5)$ & $9.5(2.5-14.8)$ \\
\hline $\begin{array}{l}\text { Physical burden } \\
\text { (maximum = 20) }\end{array}$ & $10.0(7.5-12.0)$ & $5.0(1.0-7.8)$ \\
\hline $\begin{array}{l}\text { Social burden } \\
\quad(\text { maximum = 16) }\end{array}$ & $6.0(4.0-7.5)$ & $4.5(1.5-6.8)$ \\
\hline $\begin{array}{l}\text { Emotional burden } \\
(\text { maximum }=20)\end{array}$ & $1.0(0.0-2.0)$ & $0.5(0.0-2.0)$ \\
\hline
\end{tabular}

Data presented as median (interquartile range)

Two caregivers believed that they had enriched their own lives by becoming an informal caregiver, due to their personal religious beliefs and personal enjoyment. Many caregivers indicated that they did not regret their decision to care for their loved one at home seeing the sense of satisfaction of the patient and being aware of their sense of duty.

Restriction on day-to-day life

All caregivers believed that they had been deprived of leisure time as a result of the VAI's constant care needs. The amount of time varied with how much other support, from family or social services, they received. Many believed that this caregiver role had deprived them of things taken for granted by others of their age and described being stripped of their own enjoyment due to caring for their loved one $24 \mathrm{~h}$ a day

PC1: I am a prisoner in my own home, at my own will. Although I don't regret it, this is the way I feel.

PC3: But it's being deprived of my life, of my family, of my future, of my expectations, of my retirement, of everything, it's gone.

Caregivers felt chained to the house because they often could not leave their loved one for even a short time. Although they could do tasks around the house in between interruptions, they could not live as they pleased.

PC6: I find it frustrating that you just can't do what you want. You have to be prepared to be interrupted at anytime when he needs me.
PC11: Being at his beck and call (like get this, get that) can be frustrating. In caregiving you never get a break.

Caregivers who received a small amount of free time weekly commented on the positive impact on their lives. In contrast, those who were receiving direct funding while still caring for the VAI felt substantially less deprived, although it remained an issue of importance.

PC12: I enjoy when sometimes I want to go out the caregiver is here, so I can easily go.

Secondary caregiver (SC)1: I have four hours twice a week when I can go out and be with other people and have some release. It is very little but it is something.

Although all caregivers were allotted a fixed number of hours from various health care and social service agencies, many had difficulty in delegating tasks or expressed a lack of confidence in the paid help. All caregivers struggled with changes in hired support personnel due to the new person's unfamiliarity with the procedures, the patient or the schedules.

SC5: So I have to be with him all the time whenever they [paid caregivers] come. I have to tell them what to do.

PC9: It's not that I don't trust anybody, but I'd rather be here.

The encroachment on caregiver's time impacted their employment. Some noted that in addition to the high expense of equipment and paid care, their inability to advance or maintain a job was extremely restricted. Even those who had direct funding and were able to maintain employment indicated that it was at a level below their potential.

PC9: That put me back years in terms of any career movement and also caused me to lose quite few hundreds of thousands of dollars in terms of salary that I could have earned then and in the future.

This theme was supported by the high scores on the CBI timedependent domain (Table 2).

Physical and emotional burden

Caregivers who had cared for loved ones for more than 10 years often had physical ailments, which they attributed at least in part to the long period of care. The many years of ongoing care, the increasing levels of dependency and the increasing age of caregivers were all mentioned as compounding the physical stress leading to or aggravating debilitating ailments.

PC4: I have fibromyalgia, there are things for which it's hard for me to help him as my hands and muscles get stiff. I have a herniated disc too. I think it was all from him.

SC7: I've had two knee replacements. I'm not physically strong but I give every ounce of strength that I've got every day. 
All caregivers interviewed believed that they did not always get enough sleep, leaving them tired throughout the subsequent days and decreasing their ability to provide care for the VAI and impacting their health.

PC2: So even at night when you sleep you're sleeping with one eye open. I'm a very light sleeper and I've been having a problem for many, many years because of lack of sleep.

Emotionally, caregivers found it difficult if they were unable to speak fluently with their loved one. One-third of caregivers expressed that they felt extremely depressed by the situation they found themselves in, with most having been prescribed antidepressants in the hope to combat these symptoms. Caregivers primarily described their own situation, and their lack of an independent life contributed to their depression and the condition of their loved one was rarely mentioned.

SC7: I have depression and I feel sad most of the time. Sometimes I say I hate my life, I wish I was dead.

The emotional burden scores of the CBI were fairly low (Table 2); however, the questions are predominantly about how the caregiver feels about the patient rather than their situation.

\section{Training and education}

All caregivers, except two, believed that the training they had received (at the ventilator centre) in preparation for home ventilation, was extremely good. However, many remained apprehensive with regard to having nowhere to turn to for help in dealing with unexpected problems.

PC2: Every day goes by and I don't know what to expect. I remember calling the hospital because there was something with her that wasn't quite right. I just needed someone to call but there was nobody to call.

SC1: It was very hard, to come home the first time after the hospital. Even though we got trained you don't know what to expect, so it was very difficult. Over time I learnt what to do.

The majority of caregivers reported that the time soon after their loved one returned home (the first couple months) had been the most difficult time, although things became easier over the subsequent months and years. Becoming more accustomed to the various procedures, better scheduling, consistent nursing support all helped them become more comfortable with caring for a VAI at home.

SC3: It is quite overwhelming at the beginning.

SC5: In the beginning it was hard. I was so scared bringing him home.

SC6: Definitely the first three days were so scary because, you know, it's the first time.

Several caregivers were unaware of the progression of their relative's disease, and were not prepared for what may happen in the future whereas some actively refused to think about the future. They believed it was too depressing and that everything that could have happened had already happened. Others describe never formally being informed of how the disease would progress. Those who acknowledged understanding the disease and its progression believed that this was extremely helpful.

PC1: It's not enough to only teach the medical things, you need to know what to expect in the long run. Knowing about the disease really helps."

\section{The need for more paid support}

Caregivers without direct funding believed that they did not have enough support to give adequate care to their loved ones, many envisioning the possibility of caregiver 'burn-out' for both themselves and others in their position.

SC5: Because it is a big job they should arrange for more help...
PC8: I think we are going to need a lot more support. I cannot see a lot of people doing this stuff without it affecting the family. I cannot see a lot of people doing what I'm doing at home, I really can't.

\section{DISCUSSION}

The present study was the first to exclusively evaluate caregiver burden for those caring for family members with progressive NMD who also require $24 \mathrm{~h}$ invasive ventilation. It expands the current literature because the complexity of caring for family members with both conditions is likely to be greater than when caring for either alone. Home ventilation has become an important focus of care, both in Europe $(32,33)$ and in North America (34). The present study highlights the commitment made and sustained by the informal caregivers toward their loved ones despite the impact on their lives. At the time of the interview, this commitment had already been sustained for many years. It was associated with a substantial burden on the caregivers' lives despite the strong duty for care they described. Five main themes emerged: a sense of duty; restriction of day-to-day life; physical and emotional burden; training and education; and the need for more paid support.

As demonstrated by the interview responses and the time-dependent $\mathrm{CBI}$ domain, caregivers felt markedly constrained by the time requirements of caring for a VAI, which, in some instances, were considered to be so substantial as to have 'robbed' them of their own lives. Most caregivers described restriction to almost all parts of life: careers, finances, hobbies and leisure time, and many hardly left the house at all. This burden was supported by the high total CBI scores: similar to caregivers of patients with spinal cord injuries (30) and Alzheimer's disease (31), but were even higher in the time-dependent CBI domain. The CBI results were consistent with those described in ALS with the highest level of dependency (13).

Most of the caregivers identified both a physical and an emotional burden associated with caring for their loved ones. Many attributed the hard work to the development of chronic conditions, and many identified anxiety and depression as part of their lives. This supports observations by Hecht et al (19) in which 'physical and emotional' burden were among the most pressing issues for caregivers of patients with ALS. In the current study, lack of sleep was frequently cited as a contributor to physical and emotional burden, and this was often related to concerns about the ventilator. Being unable to communicate easily with loved ones was especially frustrating. Feelings of depression were expressed by one-third of our caregiver population, which is consistent with other studies dealing with caregivers of loved ones with $\operatorname{NMD}(12,13)$ and those invasively ventilated (35). It would, therefore, seem advisable to include ongoing screening for depression in caregivers, to enable appropriate management to be implemented.

The notion of insufficient funded care was frequently expressed, even by those receiving substantial support through social services or private insurance. Caregivers pointed out that even a small amount of funded support positively influenced their situation by enabling them to leave the home and pursue their personal needs. However, many reported inconsistency in the availability of paid support and the disruption caused by any change in formal care personnel. This led to some being unable to delegate even when other caregivers were available.

\section{Practical implications}

All patients and their caregivers completed a formal training program of ventilator care that included written material, personal teaching on the underlying medical condition and how to recognize a variety of respiratory needs, training in emergency management and who to contact. This training also included information on funding resources. Patients were not discharged from the training program until they had successfully completed a weekend trial at home so that any issues of concern could be addressed by the team. At home, caregivers were 
provided with a $24 \mathrm{~h}$ number to call. The fact that the absence of ongoing support was frequently expressed by the caregiver suggests that the training program may need to ensure that the information provided is understood and internalized by the caregivers. The lack of support was especially noted during the initial months of the VAI returning home. The majority of caregivers noted this to be the most stressful part of the process, during which time they often felt alone with no one to turn to for assistance. A post-training assessment for discussion, questions and assessment of the caregivers' skills with scheduled regular follow-up should be considered as part of the ventilator training program. Support needs to be increased during the initial few weeks. Conceivably, more involvement of caregivers when the option of home ventilation is under consideration would enable them to participate more fully in an informed decision, thereby reducing some of the overwhelming feelings that they experienced.

Consideration of the perspectives reported by caregivers raises several other issues that might improve care of VAIs with a high level of impairment. Professional support should especially be increased at the time of transition home. Improved funding through government agencies would enable family caregivers to participate more in their own lives and not be totally subjugated to the needs of the VAI. Training, even at a centre of excellence for long-term ventilation, appears to be insufficient unless accompanied by home follow-up. The availability of a telephone or Internet-based call system to address more immediate needs could assist in addressing the isolation expressed by the caregivers.

Similar to many individuals with ongoing conditions $(36,37)$, care might be enhanced by a closer integration between the hospital-based ventilator care team and the community primary care providers. Improved monitoring will then enable the health care system to quickly recognize potential health issues and address them before an acute admission becomes the only option. It will also extend the care of the VAI to include the physical and emotional needs of the caregivers. Finally, the provision of respite care for the VAI may relieve some of the caregiver stress and thereby maintain the viability of a home-based system. This could include one week annually, during which time the patient's medical and social needs could be re-evaluated.

The line of inquiry in the present study was focused on documenting the burden associated with informal caregiving in this specific population to comment on areas that could be addressed to make home ventilation a more sustainable approach for patients with progressive NMD. There was minimal response to the single question (question 4) that inquired as to which aspects of caregiving the family members enjoyed. Conceivably, a series of questions focused on the positive aspects of this situation may have yielded more information.

\section{CONCLUSION}

Although home ventilation maximizes independence and improves quality of life for the VAI $(1,15,17,38,39)$, it is accompanied by a substantial burden to the lives of the family caregivers. These burdens include time, financial, emotional and medical constraints. Approaches to improve caregiver well-being, such as more professional support and respite care, may enable home ventilation to be a more sustainable modality of care.

AUTHOR CONTRIBUTIONS: Dr Evans contributed to the study design, data analysis and interpretation, and writing the manuscript. Mr Catapano contributed to the data collection, data analysis and interpretation, and writing the manuscript. Dr Brooks contributed to the study design, data analysis and interpretation, and revising the manuscript. Dr Goldstein contributed to the study design, data analysis and interpretation, and writing the manuscript. Dr Avendano contributed to the study design, data analysis and interpretation, and revising the manuscript.

DISCLOSURES: The authors have reported to the Canadian Respiratory Journal that no potential conflicts of interests exist with any companies/ organizations whose products or services may be discussed in this article.

12. Trail M, Nelson ND, Van JN, Appel SH, Lai EC. A study comparing patients with amyotrophic lateral sclerosis and their caregivers on measure of quality of life, depression, and their attitudes toward treatment. J Neurol Sci 2002;209:79-85.

13. Chio A, Gauthier A, Calvo A, Ghiglione P, Mutani R. Caregiver burden and patients' perception of being a burden in ALS. Neurology 2005;64:1780-2.

14. Adelman BR, Albert SM, Rabkin JG, Del Bene ML, Tider T, O'Sullivan I. Disparities in perception of distress and burden in ALS patients and family caregivers. Neurology 2004;62:1766-70.

15. Winter Y, Schepelmann K, Spottke AE, et al. Health-related quality of life in ALS, myasthenia gravis and facioscapulohumeral muscular dystrophy. J Neurol 2010;257:1473-81.

16. Ambrosino N, Carpene N, Gheradi M. Chronic respiratory care for neuromuscular diseases in adults. Eur Respir J 2009;34:444-51.

17. Narayanaswami P, Bertorini TE, Pourmand R, Horner LH. Long-term tracheostomy ventilation in neuromuscular diseases: Patient acceptance and quality of life. Neurorehabil Neural Repair 2000;14:135-9.

18. Kaub-Wittemer D, von Steinbuchel N, Wasner M. Quality of life and psychosocial issues in ventilated patients with amyotrophic lateral sclerosis and their caregivers. J Pain Symptom Manage 2003;26:890-6.

19. Hecht MJ, Graesel E, Tigges S, et al. Burden of care in amyotrophic lateral sclerosis. Palliat Med 2003;17:327-33.

20. van Kesteren RG, Velthius B, van Leyden LW. Psychosocial problems arising from home ventilation. Am J Phys Med Rehabil 2001;80:439-46.

21. Brooks D, King A, Tonack M, Simson H, Gould M, Goldstein RS. User perspectives on issues that influence the quality of daily life of ventilator-assisted individuals with neuromusclar disorders. Can Respir J 2004;11:547-54.

22. Tasara V, Serasli E, Voutsas V. Burden and coping strategies in families of patients under noninvasive home mechanical ventilation. Respiration 2006;73:61-7. 
23. Thommessen B, Aarsland D, Braekhus A, Oksengaard AR, Engedal K, Laake $\mathrm{K}$. The psychosocial burden on spouses of the elderly with stroke, dementia and Parkinson's disease. Int J Geriatr Psychiatr 2002;17:78-84.

24. Braun V, Clarke V. Using thematic analysis in psychology. Qual Res Psychol 2006;3:77-101.

25. Kidd D, Stewart G, Baldry J, et al. The functional independence measure: A comparative validity and reliability study. Disabil Rehabil 1995;17:10-4.

26. Pasqua F, Biscione GL, Crigna G, et al. Use of functional independence measure in rehabilitation of inpatients with respiratory failure. Respir Med 2009:103:471-6.

27. Strauss A, Corbin J. Basics of Qualitative Research. London: Sage Publications, 2011.

28. Caserta MS, Lund DA, Wright SD. Exploring the caregiver burden inventory (CBI): Further evidence for a multidimensional view of burden. Int J Aging Hum Dev 1996;43:21-34

29. Novak M, Guest C. Application of a multidimensional caregiver burden inventory. Gerontologist 1989;29:798-803.

30. Gajraj-Singh P. Psychological impact and the burden of caregiving for persons with spinal cord injury (SCI) living in the community in Fiji. Spinal Cord 2011;49:928-34.

31. Akpinar B, Kucukgucku O,Yener G. Effects of gender on burden among caregivers of Alzheimer's patients. J Nurs Scholarsh 2011;43:248-54.
32. Farre R, Lloyd-Owen S.J, Ambrosino N, et al. Quality control of equipment in home mechanical ventilation: A European Survey. Eur Respir J 2005;26:86-94.

33. Lloyd-Owen SJ, Donaldson GC, Ambrosino N, et al. Patterns of home mechanical ventilation use in Europe: Results from the Eurovent survey. Eur Respir J 2005;25:1025-31.

34. McKim DA, Road J, Avendano M, et al. Home mechanical ventilation: A Canadian Thoracic Society clinical practice guideline. Can Respir J 2001;8:197-215.

35. Douglas S, Daly BJ. Caregivers of long-term ventilator patients. Chest 2003;123:1073-81.

36. Coleman K, Austin BT, Brach C, Wagner EH. Evidence on the chronic care model in the new millennium. Health Aff (Millwood) 2009;28:75-85

37. Rothe U, Muller G, Schwarz PE, Seifert M, Kunath H, Koch R. Evaluation of a diabetes management system based on practice guidelines, integrated care, and continuous quality management in a Federal State of Germany: A population-based approach to health care research. Diabetes Care 2008;31:863-8.

38. Geisler J, Karg O, Borger S, Becker K, Zimolong A. Invasive home mechanical ventilation, mainly focused on neuromuscular disorders. GMS Health Technol Assess 2010;14:6-8.

39. Moss AH, Casey P, Stocking CB, Roos RP, Brooks BR, Siegler M. Home ventilation for amyotrophic lateral sclerosis patients. Neurology 1993;43:438-43. 


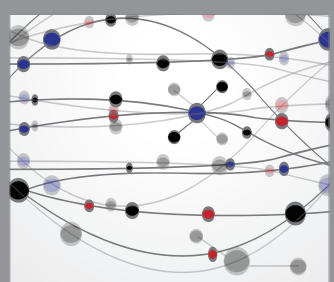

The Scientific World Journal
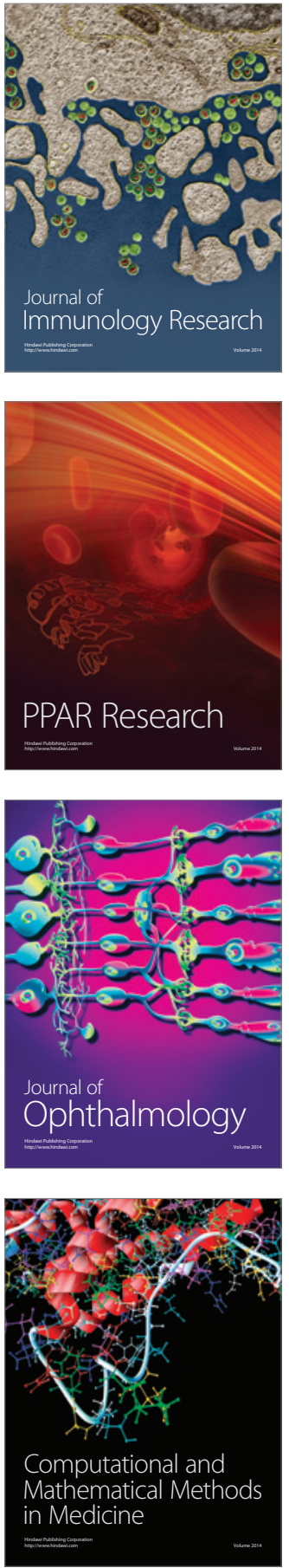

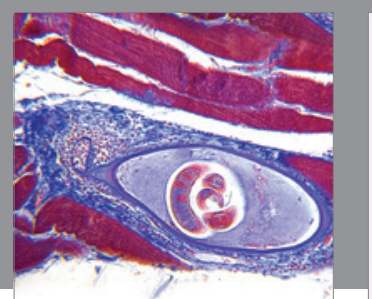

Gastroenterology Research and Practice

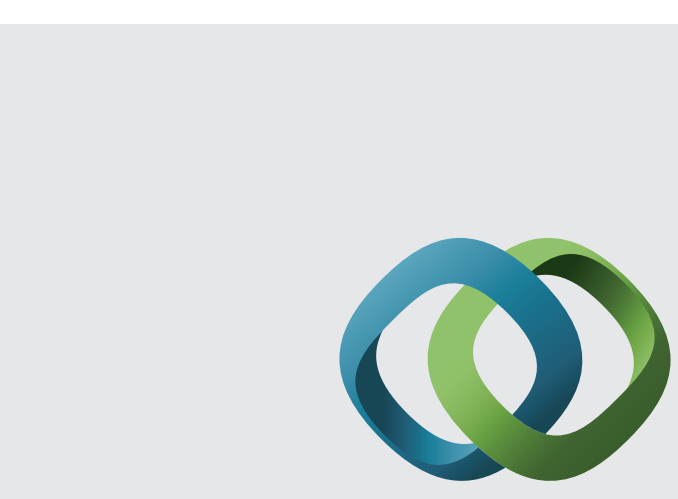

\section{Hindawi}

Submit your manuscripts at

http://www.hindawi.com
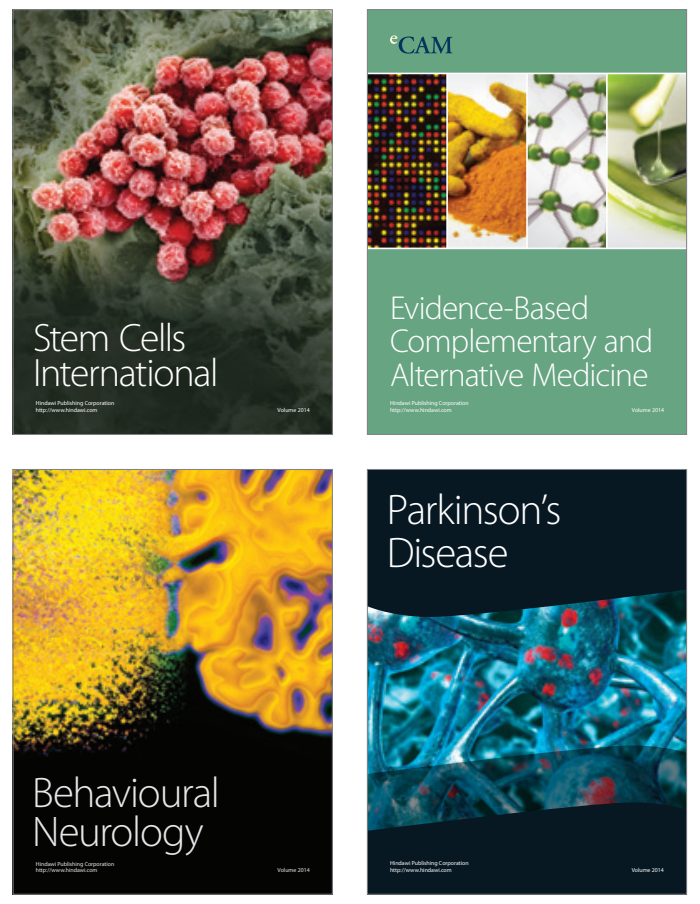
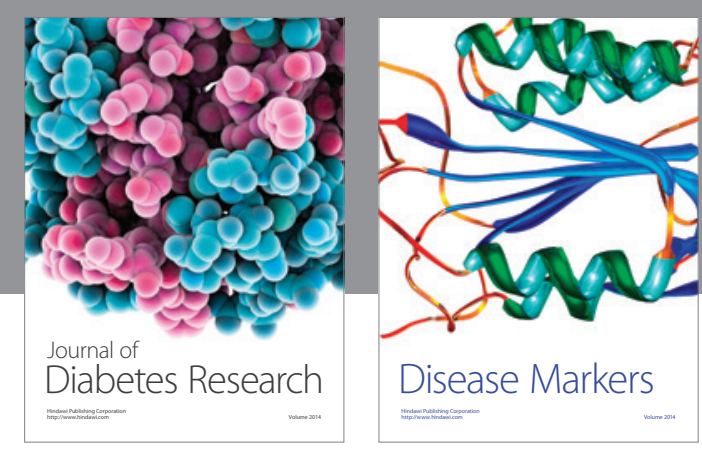

Disease Markers
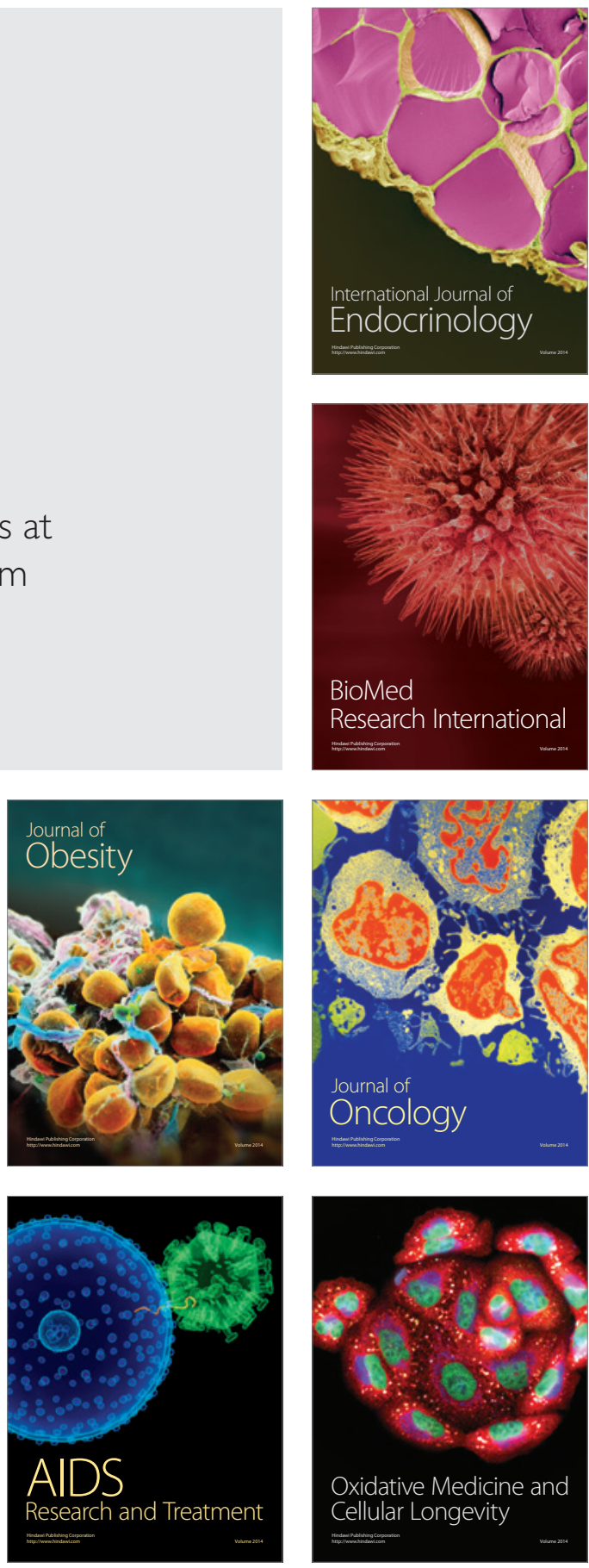